\title{
EXPLICIT AND IMPLICIT WAYS OF ENHANCING COMMON GROUND IN CONVERSATIONS
}

\author{
Andreas H. Jucker and Sara W. Smith
}

\section{Introduction 1}

A statement from Stalnaker which he presented as a truism some twenty years ago may serve as our starting point:

Communication, whether linguistic or not, normally takes place against a background of beliefs or assumptions which are shared by the speaker and his audience, and which are recognized by them to be so shared [...]. The more common ground we can take for granted, the more efficient our communication will be. And unless we could reasonably treat some facts in this way, we probably could not communicate at all (Stalnaker 1974[1991]: 472).

In this paper we want to explore the notion of common ground and its theoretical status, and we want to illustrate how conversationalists attend to their common ground, how they negotiate, maintain and enlarge it. This is part of a larger claim that much of language use consists of interlocutors' negotiation of common ground. This may happen, as we shall illustrate below, on a fairly explicit turn-by-turn level when interlocutors interrupt each other to establish the correct identity of a referent or when they ask each other to confirm assumptions, and it happens implicitly on a sentence-by-sentence level as interlocutors signal their assumptions by their linguistic choices.

\section{1.l Common ground}

The concept of shared beliefs and assumptions and its impact on communication have been discussed by many writers under many different names and in different theoretical frameworks, as for instance pragmatic presuppositions (Stalnaker 1974[1991], Caffi 1994); mutual knowledge (Smith 1982; Gibbs 1987; Perner and Garnham 1988); shared assumptions (Sperber and Wilson 1986); scripts (Schank and Abelson 1977); and common ground (Clark

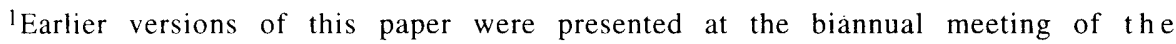
Swiss Association of University Teachers of English (SAUTE), May 12-13, 1995, in Berne, Switzerland, and at the 3rd ESSE Conference, September 8-12, 1995, in Glasgow, Scotland. Our thanks go to the audiences at the two conferences, to Lachlan Mackenzie, the convener of our section at Glasgow, and in particular to an anonymous reviewer.
} 
1992; Gibbs 1987). It is not our intention to review these notions in detail in this context. The term "mutual knowledge" is probably the most common of these. However, Sperber and Wilson (1986: 19f), for instance, argue very strongly against the concept of mutual knowledge on the grounds that interlocutors can never have any certainty about each other's knowledge and beliefs. Mutual knowledge, according to Sperber and Wilson, must be certain, or else it does not exist; and since it can never be certain, it can never exist (Sperber and Wilson 1986; for opposing views see Gibbs 1987 or Perner and Garnham 1988). Sperber and Wilson only allow for assumptions that interlocutors can have about each other's assumptions. We take it to be uncontroversial that interlocutors can never have ultimate certainty about each other's assumptions or knowledge. But the term "knowledge" does not prejudge the issue. We shall use it occasionally to refer to the set of assumptions entertained by an interlocutor. Some of these assumptions will be strong, others only weak, and they will include assumptions about the addressee's assumptions.

We use the term "common ground" to refer to those assumptions which are entertained by both partners in a conversation and which they assume to be so shared. Obviously, such assumptions are easier to judge under some circumstances than others; there is a continuum from the situation in which both partners are jointly observing a common and salient event to the situation in which one must make judgements based on assumptions about another person's presumed earlier exposure to an event (cf. Clark 1992).

Besides determining whether a partner has been exposed to information, a speaker must make assumptions about the linguistic contexts in which that information will be accessible to the partner; e.g., what choice of nouns and modifiers will identify a referent?

For interlocutors who share a common culture, much common ground comes from culturally-shared activities, or scripts, as described by Schank and Abelson and others. A text like the following activates a script that fills in the gaps in the description of events.

(1) John went to a restaurant. He asked the waitress for $\operatorname{coq}$ a u vin. He paid the check and left. (Schank and Abelson 1977: 38)

To a large extent, a speaker works from assumptions based on judgements about membership in socio-cultural categories. People from a western country are assumed to share much cultural knowledge, including such scripts as the restaurant script. Even strangers, if they realise each other to have a similar cultural 
background, can take a certain amount of shared cultural knowledge for granted. A car driver looking for a street in an unfamiliar town will assume that a man coming out of a local shop will know the location of the street and will be able to give her directions how to get there.

Individuals who have shared an event such as a dinner together will, of course, make assumptions about each other's knowledge of that event. However, as we shall see later, a shared experience is itself no guarantee that partners will be able to identify the relevant common ground. Making judgements about what information a partner will remember and under what circumstances it will be accessible requires quite elaborate social and metacognitive judgments. While partners may often be able to depend on implicit signals to convey and confirm their assumptions, they may also need strategies for the explicit negotiation of even known common ground.

Intimates, such as family members or close friends, obviously share a lot of common ground while non-intimates (typically acquaintances) share less common ground and distants (typically strangers) share very little common ground other than a fuzzy set of basic cultural knowledge. But we want to argue that even intimates must constantly negotiate and renegotiate their common ground.

We propose to demonstrate that a) intimates are able to carry out much of their negotiation through implicit means, but b) even intimates must often resort to explicit negotiation strategies when their assumptions do not appear to be met, and c) in order for these negotiations to be successful, partners must build on their acknowledged common ground. Finally we would argue that, as partners negotiate and exploit their common ground, they thereby enhance it so that it becomes both more certain and more accessible for future use.

We shall illustrate our argument with extracts from a four-party dinner table conversation between two sisters in their late fifties or early sixties and their respective husbands. The recording was made non-surreptitiously in 1985. MA and her husband WA have just returned from a visit to Australia. They have invited BE and DA for dinner to tell them about their trip. The entire conversation covers a range of topics, but most of them relate directly to MA and WA's recent trip and to advice they give $B E$, who plans to travel to Australia in the near future.

This conversation is a good example of an interaction between intimates. These four people have known each other for a very long 
time, they share many experiences, and they have had similar conversations on many previous occasions. There are, therefore, allusions and hints which are incomprehensible to the uninitiated.

In addition, all four of them share the same cultural background. They live in the same region of England, they belong to the same social class and to the same age group.

However, even for them there is a lot to be negotiated. MA and WA, who jointly tell several stories about their experiences in Australia, often have to reestablish their common ground in some areas in order to negotiate some of the details needed for the current conversation. Several of the following extracts will show very clearly that even shared experiences do not guarantee mutual knowledge in the strict sense because the speakers may remember different details or they may remember the same event in a different way.

\subsection{Basic model}

We claim that various aspects of language exist, not only to convey information or to express social relations, but also to help us create models of each other's presumed knowledge (cf. Smith and Jucker 1995 ).

Ordinarily, conversationalists provide each other with a variety of cues that assist in the on-line detection of common ground and facilitate the constant adaptation of their language to it.

The basic choice of whether to make an assertion or ask a question depends on the assessment of whether the speaker or hearer is most likely to have the target information, as in Julie likes ale vs. Does Julie like ale? A variety of syntactic choices also convey assumptions about H's knowledge. Tag questions (Houck 1991) with either rising or falling intonation, for instance, (Julie likes ale, doesn't she? vs. Julie likes ale, doesn't she.), convey assumptions about the relative certainty with which the speaker or the hearer is assumed to have access to relevant information.

Forms of reference, such as definite or indefinite (Prince 1981; Jucker 1992), the use of proper names in various forms, the use of pronouns, or the amount of elaboration of a noun phrase all convey assumptions about the hearer's ability to identify and access the referent.

The high-rise question contour in English is employed to "convey that the propositional content of the utterance is to be added to speaker and hearer's 'mutual beliefs' (those shared by speaker and hearer and believed by them to be so shared), and to question whether the hearer can relate that propositional content to the contents of the hearer's own (unshared) beliefs" (Hirschberg and 
Ward 1995: 407). In the following exchange, for instance, the caller instructs the DJ to add the information that she comes from Skokie to their mutual beliefs or common ground, and at the same time she asks him whether Skokie is familiar to him, i.e. whether it is part of his private beliefs.

(2) Chicago radio station DJ: Good morning Susan. Where are you calling from? Caller: I'm calling from Skokie?

Finally, a variety of discourse markers, such as you know (Schiffrin 1987a, 1987b), actually and in fact (Green 1989), and well (Jucker 1993, Schiffrin 1987a), convey assumptions that the utterance is either consistent or inconsistent with H's presumed knowledge and beliefs.

(3) Julie likes ale, you know.

(4) Actually, Julie likes ale.

(5) Well, Julie likes ale.

While analyses of specific structures and discourse markers have often invoked common ground as a partial explanation for a linguistic choice, these analyses appear not to have been integrated into an overall model or used for an overall analysis of actual conversations. Our paper will attempt to demonstrate some of the strategies speakers use in conveying and confirming their assumptions about each other.

We want to focus on the participant's attention to her partner's knowledge, and therefore we use the term "negotiating common ground" to refer to the means by which partners signal their assumptions about each other's knowledge.

\section{Implicit negotiations of common ground}

We want to illustrate the implicit negotiation of common ground with three examples: personal pronouns, definite noun phrases and tag questions. References to people are pervasive in everyday communication. In many cases no negotiation about the identity of the intended referents is needed, either because they are easily identifiable or because they are not salient enough and serve as a mere background to more important issues. In the relatively brief excerpt, there were 16 personal referents introduced only by first name, and none of them appeared to be problematic. For example, one speaker referred in passing to a person identified only as "Bill." Both partners appeared to take it for granted that the listener was able to use the context to determine which of all the Bills in the world and even which of all the Bills they knew in common was being referred to. The use of such reference conveys strong 
assumptions about the partner's ability to use the common ground. The acceptance of such reference confirms that assumption. Other people, e.g. the headwaiter and the "girls" (sic) who served a meal, are referred to by their roles, so that commonly held scripts such as the restaurant script make identification of them possible.

\section{I Personal pronouns}

Pronouns are used freely and in such a way as to exploit assumptions about interlocutors' knowledge, as for instance in extract (6):

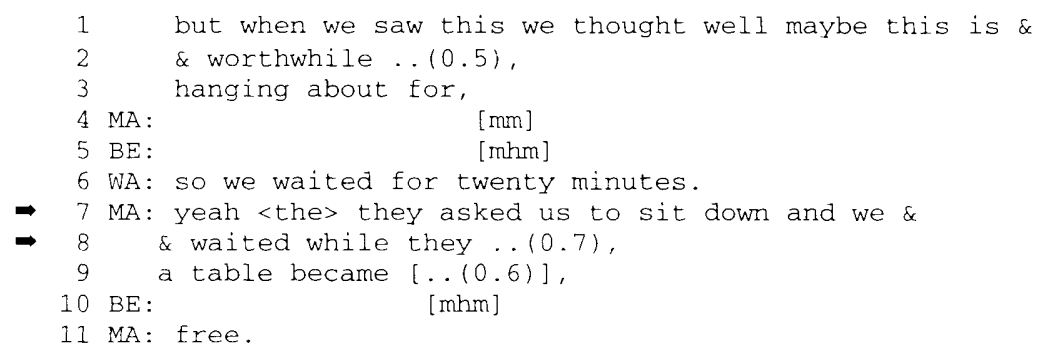

MA uses the pronoun they to refer to the staff of the Chinese restaurant; however, it does not refer anaphorically to a more explicit noun phrase earlier in the conversation, and neither does it refer exophorically to a referent in the physical surroundings of speaker and listeners. Pragmatically, the reference is unproblematic. The only maximally relevant interpretation is the one in which the pronoun they refers to those people in a restaurant who help customers find a seat. MA addresses her account to BE and DA, whom she knows to be familiar with the set-up of the average Chinese restaurant in a country of the Western world. The interactants use a Chinese restaurant script (cf. Schank and Abelson 1977). They all know each other very well and can therefore predict fairly accurately to what extent the others are familiar with this script. Fox (1987: 67) describes such references as "first mentions whose referents belonged to a general class of referents which was evoked by a frame." She points out their similarity to "frame-evoked definite NPs." But both of them are problematic for her theory, in which the use of anaphoric pronouns depends on the hierarchical structure of conversations (cf. Jucker 1995).

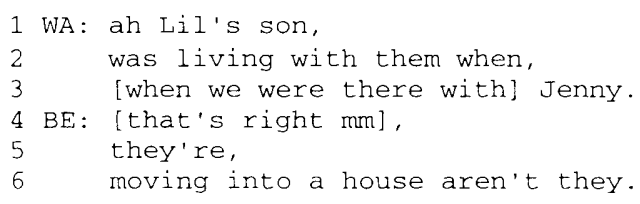




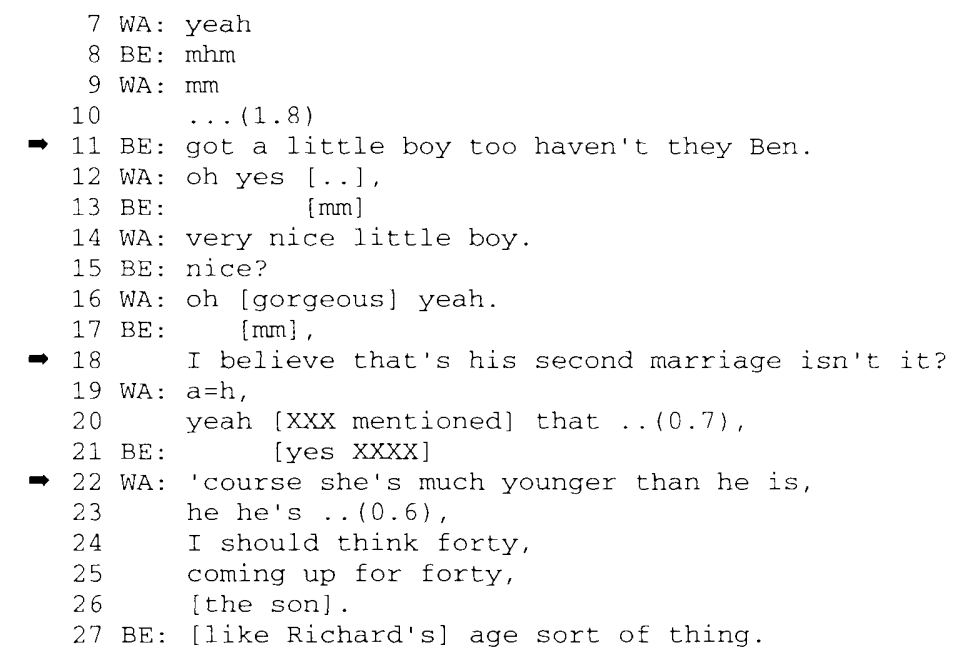

In line 1 of extract (7) WA refers to Lily's son. In the next turn, BE refers to "they" ("They're moving into a house, aren't they.") and, a few lines later, "got a little boy too haven't they Ben." A few lines later, reference is made to "his second marriage" and then that "she's much younger." While there is no syntactically defined referent for either "they" or "she," the Hearer readily interprets "they" as referring to the son and his wife as a unit and "she" as referring to the son's wife. Again, $\mathrm{S}$ is conveying and $\mathrm{H}$ confirming that both can identify the family constellation relevant to the topic.

\subsection{Definite noun phrases}

The example above shows that definite referring expressions such as pronouns need not be licensed syntactically or semantically. The same is true for the other prototypical type of referring expression, the definite noun phrase. It, too, can be used for referents that can be inferred only with the help of an appropriate script and are therefore only pragmatically licensed. Extract (8) shows such a definite noun phrase that is used without being licensed syntactically:

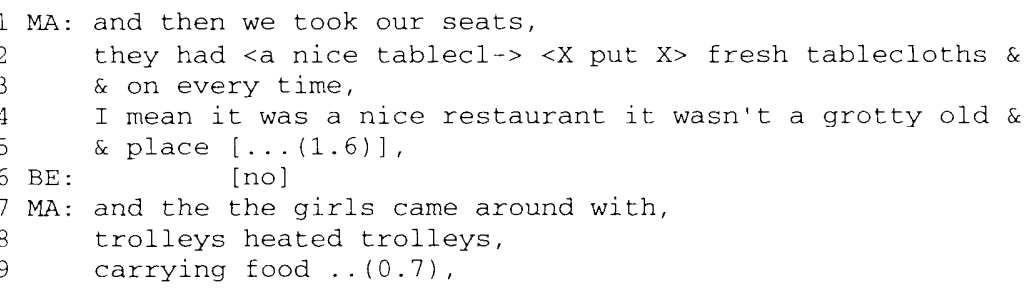


In line $7 \mathrm{MA}$ uses the definite noun phrase the girls to refer to the waitresses in the Chinese restaurant, but the noun girls has not been used before, and neither have they been referred to with any other noun phrase. The only potential coreference would be the pronoun they in lines 7 and 8 of extract (6) quoted above. But it is not very likely that MA and WA were ushered to their seats by the same waitresses who afterwards came around with heated trolleys. In fact, the pronoun they is used three times in the account of MA's and WA's visit to the Chinese restaurant. In each case, "they" seems to be defined pragmatically as "those people at restaurants who play that role."

Quirk et al. (1985: 267) use the term "indirect anaphoric reference" to refer to cases like this. A noun phrase refers back to another one with which it is associated without being coreferent with it. They give the following example:

(9) John bought a bicycle, but when he rode it one of the wheels came off.

The reference of the wheels is established through the previous mention of the noun phrase a bicycle. The addressee of this utterance will share with the speaker the assumption that bicycles have wheels. The speaker can therefore introduce them as given and uniquely identified. Notice that the use of the definite article in the phrase the wheels implies that a reference is made to all the wheels associated with the bicycle.

In (8) we would have to argue that the girls is an indirect anaphoric reference to the noun phrase a nice restaurant. However, in this case it seems unlikely that the girls refers to all the waitresses associated with this restaurant. Syntactic or semantic accounts are at a loss to explain pronoun usage and definite articles as they are exemplified in (6), (7) and (8). The reference of either the pronoun or the definite noun phrase cannot be established on the basis of the linguistic context (anaphorically) or of the extralinguistic context (exophorically). It has to be established on the basis of a script which the speaker assumes the listeners to have.

Semantically and syntactically, MA leaves out a lot of information, but in terms of relevance theory, she is optimally relevant by doing this. The waitresses were not important enough to warrant an explicit introduction. The fact that there were waitresses does not yield any contextual effects for the listeners. Their presence can be taken for granted within the Chinese restaurant script. This means that we need pragmatic principles to account for the correct interpretation. The linguistic form of a $n$ 
utterance, therefore, does not uniquely determine its propositional content.

\subsection{Tag questions}

Tag questions appear to serve several functions. Some make obviously common ground salient in the context of the current topic:

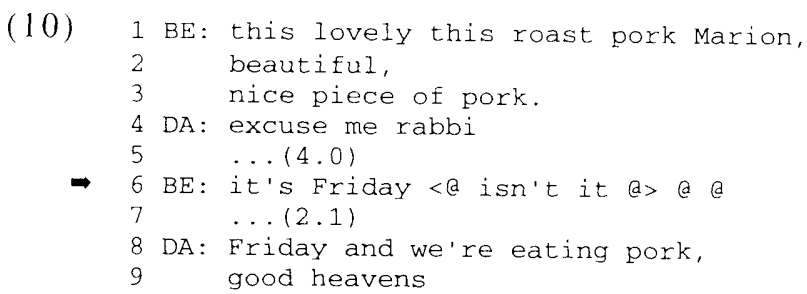

In extract (10), BE compliments the cook on the meal and in particular on the quality of the meat. DA, her husband, cracks a joke. They are eating pork on a Friday. But for four seconds nobody reacts until his wife fills in the relevant piece of background information which is needed to interpret DA's utterance in line 4. The fact that it is Friday can hardly be new to anybody but $\mathrm{BE}$ believes it to be necessary to make that information salient so the others can interpret her husband's utterance.

Other tag questions request confirmation of the speaker's beliefs in the face of some apparent differences of opinion, as for instance in extract (11). After there had been some joking around about the type of music Lily composes, BE seeks the groups's agreement on a positive view of the music, perhaps as a means of providing a closure to the topic:

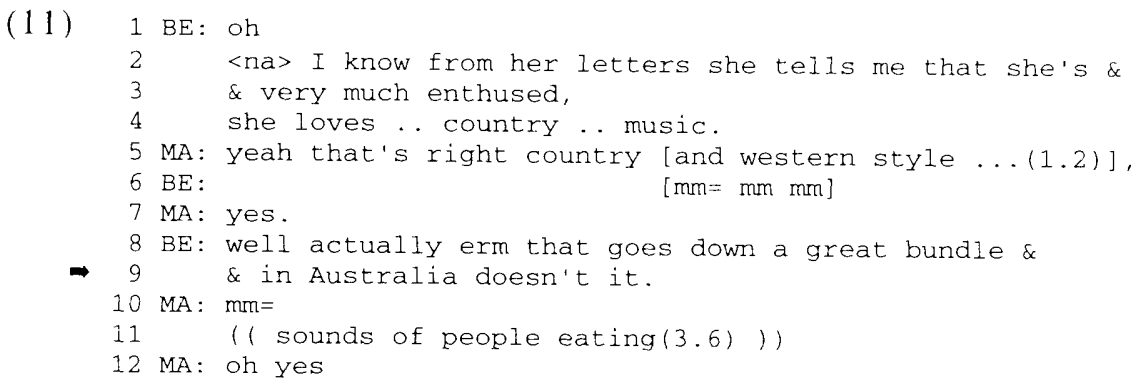

Falling intonation tags are used to seek confirmation of previously held beliefs, see lines 6 and 11 of extract (12), while rising intonation is used when $\mathrm{S}$ is less certain than she believes $H$ to be, see line 18 of the same extract (cf. Houck 1991). 


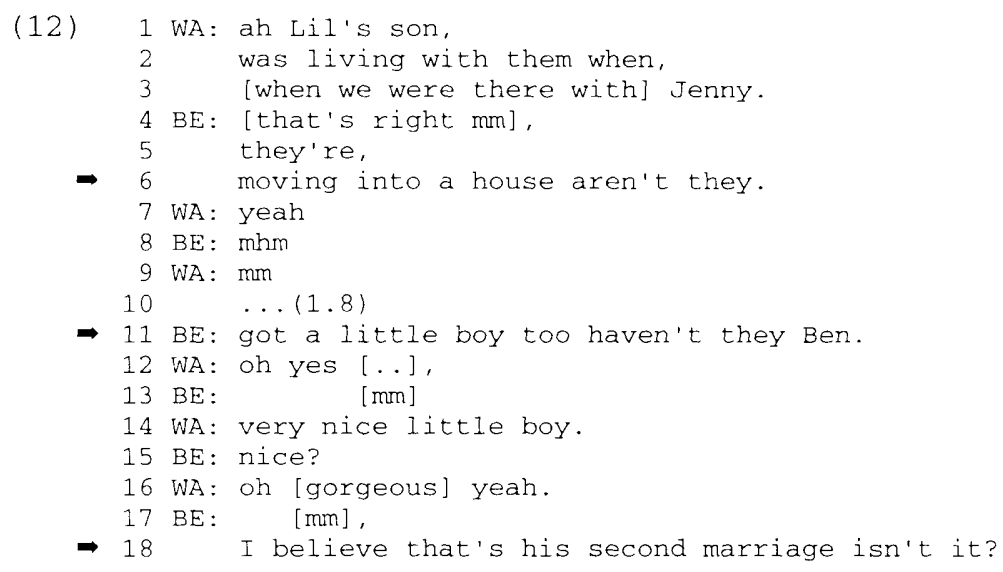

Thus, in each case, the tag questions help convey assumptions about the speaker's beliefs concerning the hearer's knowledge and beliefs, and they offer the hearer the opportunity to confirm or deny those assumptions.

\section{Explicit negotiations of common ground}

In the following we want to illustrate how conversationalists, and in particular how family members, attend to the explicit and open negotiation of common ground. We shall illustrate four different types. First, establishing correct referents; second, negotiating keylexical items; third, negotiating story details; and fourth, assessing assumptions.

\subsection{Negotiating intended referents}

Extract (13) shows a lengthy negotiation sequence in which the interlocutors try to establish the intended referent. WA wants to offer BE one of MA's hats to take to Australia. He refers vaguely to $a$ hat, but MA seems to suspect that he refers to one particular hat, viz. her dear old black hat. WA's phrase well I know another one after her first non-verbal reaction indicates that her assumption was right. There is some obvious common ground which remains hidden to the analyst. Apparently there is a hat which is very dear to MA but which WA would gladly get rid of. They both know this hat, and they know each other's feelings about it.

From this point onwards it becomes an issue to establish the correct reference of the other hat. MA suggest one possible referent, the Australian one. But WA denies this referent and describes it as the one that goes blop. At this point MA confirms that she has understood the intended reference by describing it as the nice one that Ruth gave me. Halfway through this negotiation sequence, DA 
picks up the "Australian" epithet and jokingly describes the intended referent as the one with corks. But in spite of this, and in spite of the speed of this passage and the fact that several people speak at the same time, the interlocutors, and in this case in particular MA and her husband, WA, negotiate the intended referent quickly and successfully.

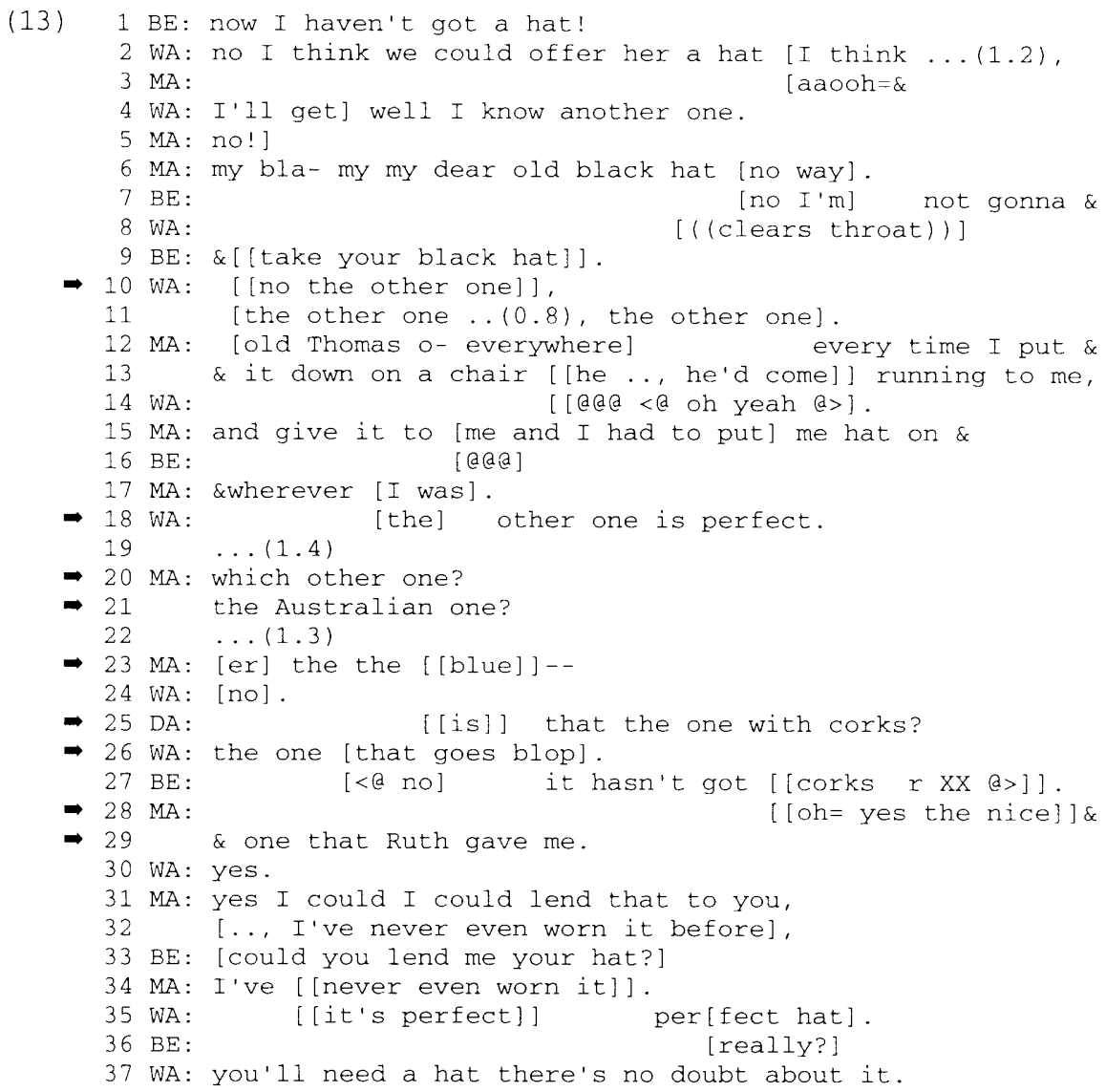

Thus, both the initial misunderstanding and the subsequent repair directly resulted from their dependence on their common ground.

\subsection{Negotiating key-lexical items}

One part of negotiation involved in communication is establishing context-specific interpretations of key-lexical items. Every lexical item can have many different referents, and for each potential referent several different lexical items could possibly be used. The intended interpretation of a lexical item can therefore only be 
established in a particular context. Examples (14) and (15) illustrate this. In (14), the conversationalists are looking for an appropriate lexical item. MA describes the object and explicitly asks her interlocutors for the name of this object. It is interesting that four different names are suggested. WA suggests harmonica and harmonium, DA offers electronic organ, while BE jokingly suggests the nonce formation lilectronic. The terms harmonium and electronic organ are mutually exclusive. One of them must be wrong but they both fit MA's rather imprecise description. Apparently the point does not warrant any further discussion. All the participants have an idea of a keyboard instrument, whether it is a harmonium or an electronic organ. and this seems to be quite adequate for the purposes.

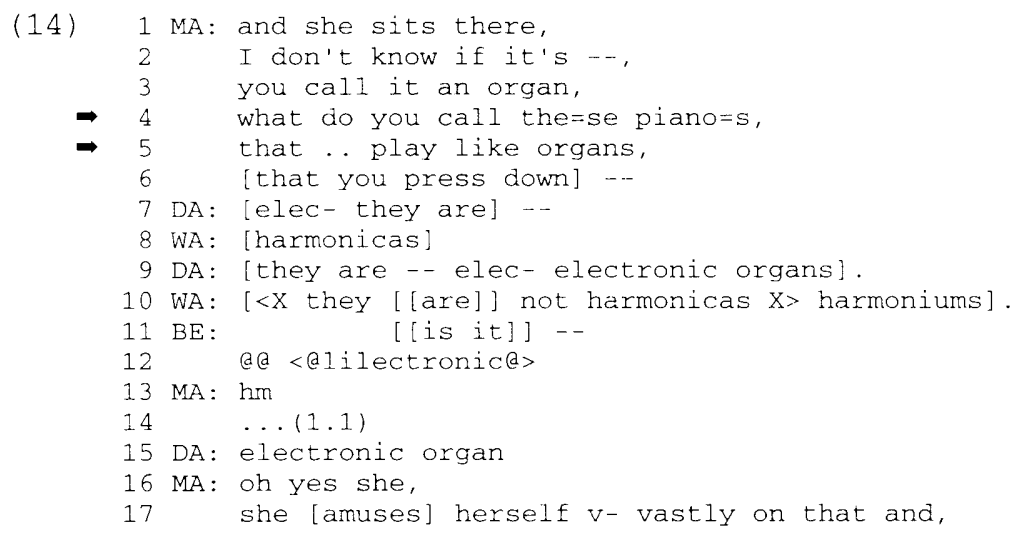

In (15) MA wants to refer to one of the characters in her Chinese restaurant story. She has a clear mental model of him but she does not know what the exact lexical label is for him. Was he the manager or the head-waiter? She asks her husband, who shares the experience of the Chinese restaurant story and can therefore be expected to be able to supply the correct label, to confirm her suggestion of manager. Even though he does confirm this lexical item, MA continues the story and refers to this character vaguely as headwaiter or manager. In spite of the apparent lack of success in establishing the correct lexical item (cf. line 9), the conversation can proceed smoothly since both descriptions identify this character as the person in charge.

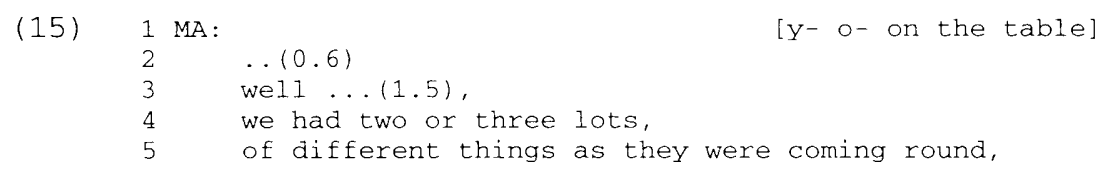




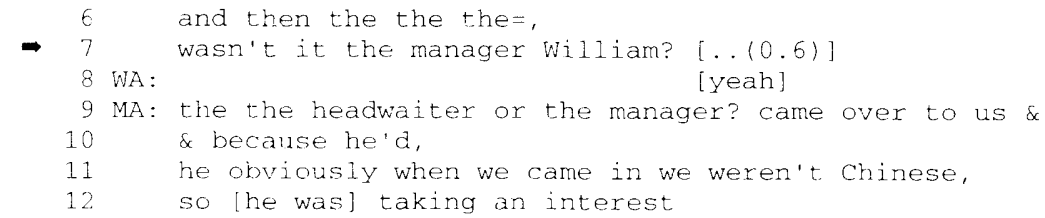

In (16) MA and WA negotiate the correct interpretation of strand. Is the area near the harbour called the strand or is the strand somewhere else? This is important for the discussion since the location of the beach is defined in relation to the strand. It turns out that WA and MA were referring to two different things by the term strand, and in the end they agree about the location of the beach, which was really what they wanted to tell BE. MA and WA use their shared knowledge in order to enhance their common ground. MA refers to "where the harbour is where we went out with the boat that time," and again to "where Rose used to go and swim." These descriptions can only help WA in the identification of the location because he shares the experience of the boat trip alluded to, and because he knows where Rose used to go and swim.

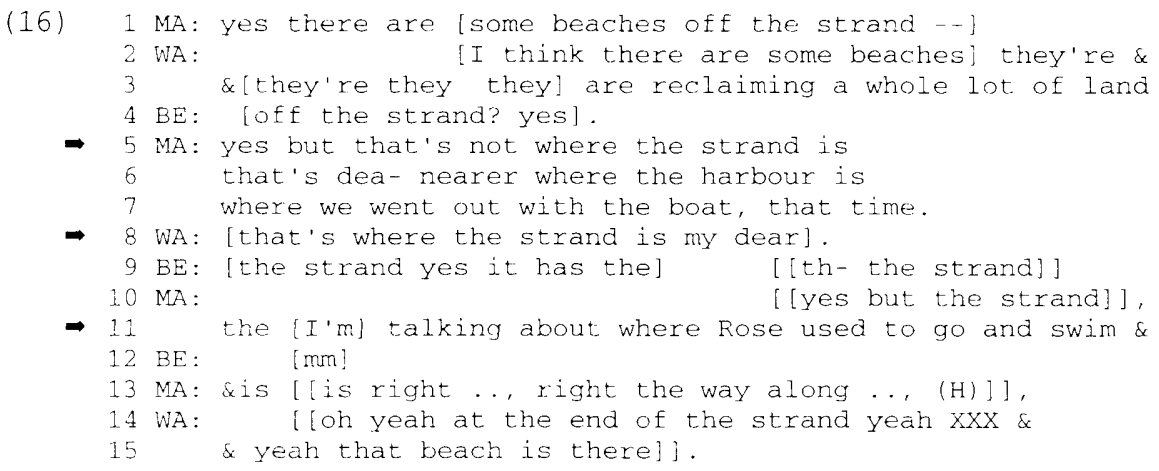

We have presented extract (16) as an example of negotiating a keylexical item in the conversation. But it might also have been discussed under the following heading, i.e. negotiating story details. In this case MA and WA are trying to create a mental map of the area, which includes the harbour, the strand, the place where Rose used to go swimming and the beach. In this endeavour it is partly a lexical problem to establish the correct referent for the term strand but it is also a question of getting the details of the map right.

\subsection{Negotiating story details}

Extract (17) shows an example in which MA cannot remember the exact date of the Chinese restaurant story. She thinks it might have 
been New Year's Day, but WA asserts that it was New Year's Eve. Thus they mutually establish a detail of their story, which in this case does not involve lexical problems.

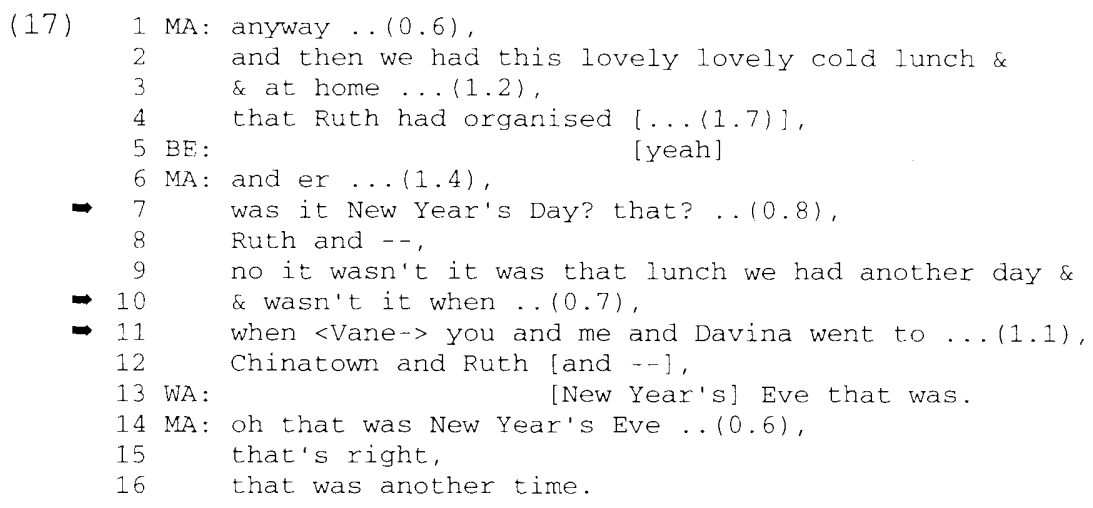

\subsection{Assessing assumptions}

Extract (18) contains a passage in which one of the participants, MA, leaves the conversation for just over 30 seconds. In the meantime, two of the remaining participants, that is her sister, BE, and WA, MA's husband, start a short conversation regarding some of their joint acquaintances and relatives in Australia. The interesting feature about this sequence is the fact that no new information is exchanged between the two. WA starts with a comment on Lil's son, who was still living with his parents when WA and MA visited them. BE, to whom this is presumably directed, not only acknowledges this piece of information but explicitly confirms it $b y$ saying That's right.

BE, then, provides various pieces of information in a rather tentative way: they're moving into a house aren't they?; they got a little boy too haven't they?; and I believe this is his second marriage isn't it? The tag questions and the preface with I believe make clear that she does not present these pieces of information as relevant for WA, but she asks him to confirm them.

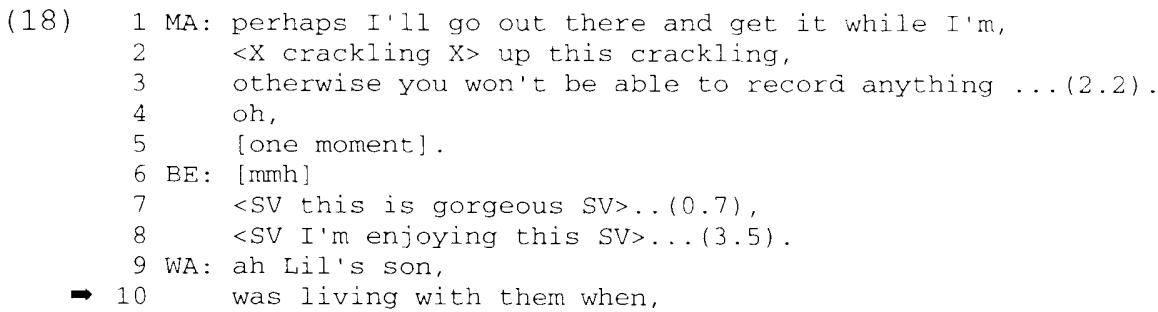




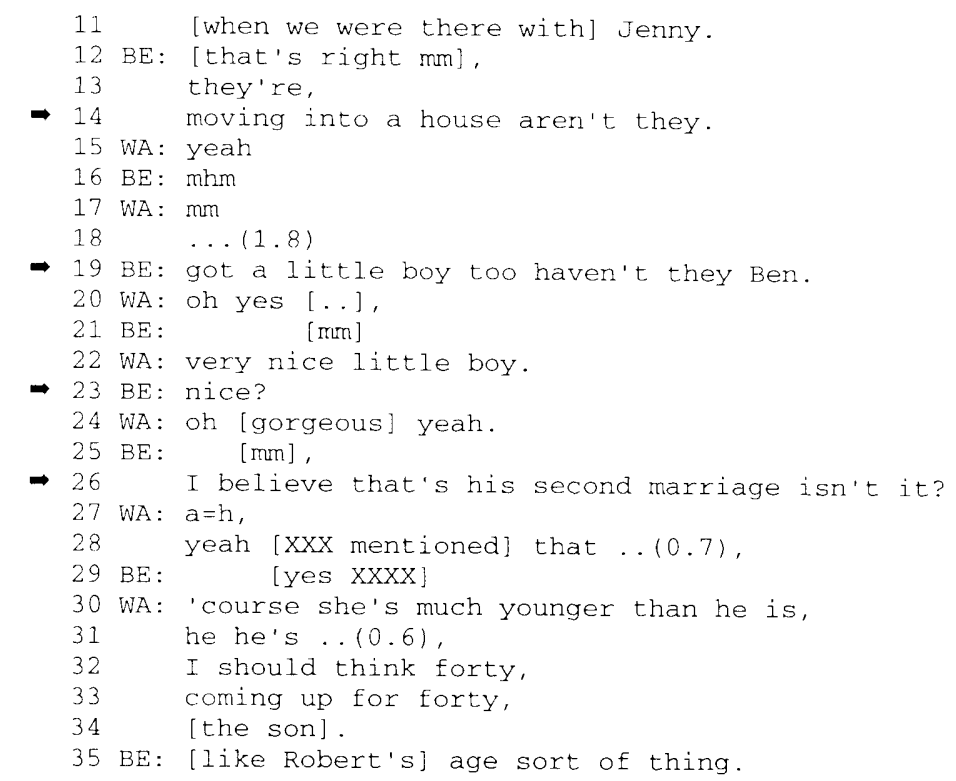

Thus, BE and WA do not exchange any information that is new to either of them. They assess their assumptions. They strengthen the certainty of existing assumptions and they establish their common ground. BE has fairly weak assumptions and checks whether WA shares these assumptions and can therefore strengthen or confirm them.

This kind of talk may be called phatic because an important function of these utterances seems to be to keep the communication channel open. They keep talking while MA is away. But the confirmation of assumptions may also serve a very important social (or interpersonal) function of maintaining a feeling of intimacy.

\section{Conclusion}

Intimates such as siblings, married couples or close friends typically share a lot of common ground. There are a lot of assumptions which they know each other to share because of their common cultural context and because of many shared personal experiences. Even when referring to shared experiences, they may need to determine whether they have the same representation of them, and they may need to make different aspects of them accessible and relevant for the partner.

However, we believe the examples above demonstrate some of the means intimates have at their disposal. First they use a number of implicit means to signal and confirm their assumptions. Referring 
expressions, for instance, are implicit means of negotiating common ground. The decision to use forms such as first names, personal pronouns, or definite noun phrases is based on the speaker's belief that the addressee will be able to uniquely identify the intended referent, and it both exploits and enhances the assumed common ground.

Communicators use tag questions to specify implicitly how they assess their common ground that is to say whether they believe their interlocutors to share some assumptions or not; or they can use tag questions as requests for confirmation, which also enhances the common ground between the conversationalists.

The examples above also demonstrate that even intimates may be required to negotiate their common ground explicitly by talking about the correct references of referring expression, by asking each other to supply a lexical item for an intended referent, by negotiating story details, or by assessing each other's assumptions. However, when they do so, they are able identify and build on previously established common ground.

We believe such elements play a critical role in the immediate interpretation of utterances and also in the creation of a model of the partner, to be used in planning and interpreting future utterances.

\section{Appendix A}

Transcription conventions based on du Bois (1991)

\section{UNITS}

Intonation unit
Truncated intonation unit
Truncated word
SPEAKERS
Speech overlap
TRANSITIONAL CONTINUITY
Final
Continuing
Appeal
LENGTHENING
Lengthening
PAUSE
Long
Medium
Short
Latching
Vocal noises
NocalseS
Exhalation
Glottal stop

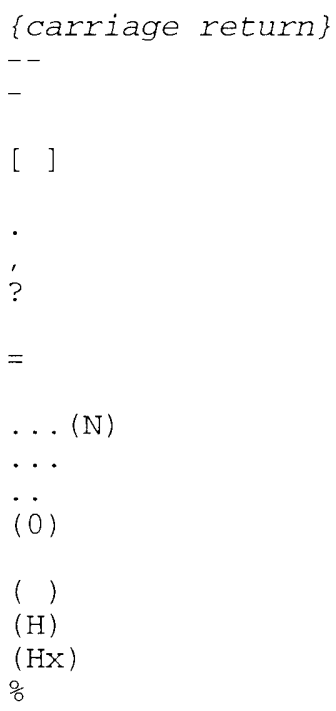




$\begin{array}{ll}\text { Laughter } & \text { a } \\ \text { QUALITY } & \\ \text { Laugh quality } & <\mathrm{Q},> \\ \text { Quotation quality } & <\mathrm{Q}> \\ \text { Sotto voce } & <\mathrm{SV} \mathrm{SV}> \\ \text { Loud } & <\mathrm{L} \mathrm{L}> \\ \text { Multiple quality features } & <\mathrm{Y}<\mathrm{Z}>\mathrm{Y}> \\ \text { TRANSCRIBER'S PERSPECIVE } & (()) \\ \text { Researcher's comment } & <\mathrm{X} \mathrm{X}> \\ \text { Uncertain hearing } & \mathrm{X} \\ \text { Indecipherable syllable } & (\mathrm{N}) \\ \text { SPECIALISED NOTATIONS } & \& \\ \text { Duration } & \end{array}$

\section{References}

Caffi, Claudia (1994) Pragmatic presupposition. In R. E. Asher (ed.). Encyclopedia of language and linguistics. Oxford: Pergamon, 3320-3327.

Clark, Herbert H. (1992) Arenas of Language Use. Chicago: University of Chicago Press.

Du Bois, John W. (1991) Transcription design principles for spoken discourse research. Pragmatics 1.1: 71-106.

Fox, Barbara A. (1987) Discourse structure and anaphora. Written and conversational English. Cambridge: Cambridge University Press.

Gibbs, Raymond W. Jr. (1987) Mutual knowledge and the psychology of conversational inference. Journal of pragmatics 11: 561-588.

Green, Georgia M. (1989) Pragmatics and natural language understanding. Hillsdale, New Jersey: Lawrence Erlbaum.

Hirschberg, Julia, and Gregory Ward (1995) The interpretation of the highrise question contour in English. Journal of Pragmatics 24. 407-412.

Houck, Noel (1991) Tag questions. A necessary pragmatic context. In: Lawrence Bouton and Yamuna Kachru (eds.). Pragmatics and language learning. Urbana IH.: DEIL, 29-38.

Jucker. Andreas H. (1992) The pragmatics of the definitive article in English. In Frens J. H. Dols (ed.). Pragmatic Grammar Components. Tilburg: Tilburg University Press, 118-133.

Jucker, Andreas H. (1993) The discourse marker well: A relevance theoretical account. Journal of pragmatics 19: 435-452.

Jucker. Andreas H. (1995) Review of Barbara A. Fox (1987 [paperback 1993]) Discourse structure and anaphora. Written and conversational English. Cambridge: Cambridge University Press. Linguistische Berichte 158, 331-333. 
Perner, Josef, and Alan Garnham (1988) Conditions for mutuality. Journal of semantics 6.3/4: $369-385$.

Prince, Ellen F. (1978) A comparison of wh-clefts and it-clefts in discourse. Language 54.4: $883-906$

Prince, Ellen F. (1981) Toward a taxonomy of given-new information. I $n$ Peter Cole (ed.). Radical pragmatics. New York: Academic Press, 22.3256.

Quirk, Randolph, Sidney Greenbaum, Geoffrey Leech and Jan Svartvik (1985) A comprehensive grammar of the English language. London: Longman.

Schank, Roger C. and R. P. Abelson (1977) Scripts, plans, goals and understanding. An inquiry into human knowledge structures. Hillsdale, New Jersey: Lawrence Erlbaum.

Schiffrin, Deborah (1987a) Discourse markers. Cambridge: Cambridge University Press.

Schiffrin, Deborah (1987b) Discovering the context of utterance. Linguistics 25.1: $11-32$.

Smith. Neil (ed.) (1982) Mutual knowledge. New York: Academic Press.

Smith, Sara W. and Andreas H. Jucker. (1995) Foregrounding the role of common ground. Paper presented at the conference on pragmatics and language learning, Urbana, Il., March 1995.

Sperber, Dan, and Deirdre Wilson (1986) Relevance. Communication and cognition. Oxford: Basil Blackwell.

Stalnaker, Robert C. (1974) Pragmatic presuppositions. In Milton K. Munitz and Peter K. Unger (eds.). Semantics and philosophy. New York: New York University Press. Reprinted in: Steven Davis (ed.). Pragmatics. A reader. Oxford: Oxford University Press, 1991, 471-482. 